\title{
CS familiarization and conditioned suppression in weanling and adult albino rats*
}

\section{LINDA M. WILSON $\dagger$ and DAVID C. RICCIO $\dagger \dagger$ Kent State University, Kent, Ohio 44242}

Twenty-three 30- and 90-day-old rats either were given 60 nondifferentially reinforced presentations of the to-be-conditional stimulus prior to fear conditioning or remained undisturbed. Following pretraining Ss experienced a series of three CS-US pairings. Subsequently, when Ss were tested for suppression of an ongoing licking response to the CS, 23-day-old Ss displayed less suppression to the CS than did adults. In addition, Ss exposed to the CS prior to conditioning demonstrated less suppression in its presence than did nonexposed Ss. It was suggested that weanlings do not demonstrate the decremental acquisition of a CER characteristic of the "latent inhibition" phenomenon seen in older rats.

A growing number of studies have shown that nonreinforced exposures of the to-be-conditional stimulus retard acquisition of the subsequent CR (Lubow \& Moore, 1959; Lubow, 1965; Carlton \& Vogel, 1967; Rescorla, 1971; Siegel, 1972). Over repeated nondifferentially reinforced presentation of the stimulus, initially elicited attentional responses to it tend to habituate. The effect apparently requires the $S$ to learn to inhibit responding to the CS.

Recently, Feigley, Parsons, Hamilton, \& Spear (1972) have investigated stimulus habituation within a developmental context. They found that weanling rats habituated to a light stimulus reliably more slowly than did older rats. These data correspond favorably with other studies in which immature organisms appear deficient in the performance of tasks requiring response inhibition (Feigley \& Spear, 1970; Schulenburg, Riccio, \& Stikes, 1971).

The present study was designed to evaluate the effect of preconditioning CS exposures on the subsequent acquisition of a conditioned emotional response (CER) in weanling, postweanling, and adult rats. Its purpose is to underscore existing differences in the learning process between immature and adult rats (perhaps through age-related attentional deficits).

METHOD
Subjects
One hundred and one male albino Sprague-Dawley rats served

*Portions of this paper were presented in partial fulfillment of the requirements for the Master's degree by the first author. This investigation was supported by Grant GB-24220 from the National Science Foundation to the second author.

$+N$ ow at the Mental Health Research Institute, University of Michigan, Ann Arbor, Michigan 48104.

f+Requests for reprints should be sent to David C. Riccio, Department of Psychology, Kent State University, Kent, Ohio 44242. as Ss. All Ss tested at 90 days of age were housed, five per cage, in wire gang cages for 3-5 days prior to testing. Ss tested at 23 or 30 days of age were housed by litter with a lactating female. Food and water were available ad lib throughout the entire preexperimental period.

\section{Apparatus}

A Lehigh Valley standard operant box served as training and testing chambers and, with slight modifications, as the preexposure and conditioning chambers. The training and/or testing compartment contained the following features. The front and rear walls were metal plate, while adjacent walls were clear Plexiglas. A drinking spout was located in the lower left front corner of the compartment, $1 \mathrm{~cm}$ above a metal plate floor. A constant specified volume of water could be dispensed through this spout into a small cup-like depression in its upper surface. The spout was connected to a Grason-Stadler drinkometer panel (Model E4690A-1).

Several modifications were made prior to use of the chamber for preexposure to tone and/or conditioning sessions. The metal plate floor was removed to expose a floor constructed of stainless steel rods $(3 \mathrm{~mm}$ diam), placed $1 \mathrm{~cm}$ apart. A discrete 1 -sec 170-V shock could be delivered to these grids from an ac shock source. Two dark-brown Plexiglas inserts were placed against the clear Plexiglas walls. An insert in front of the drinking spout prevented access to it during CS preexposures and fear conditioning trials. All modifications were intended to minimize the generalization of fear from conditioning sessions to succeeding test trials.

A 10.2-cm-square speaker was fastened to the perforated top of the chamber. The CS (a $1500-\mathrm{Hz}$ tone at 90-dB SPL attenuation) was delivered via an audio-oscillator only during appropriate CS preexposures, fear conditioning, and test sessions. The entire apparatus was housed in a sound-attenuating chamber. A $7 \frac{1}{2}-\mathrm{W}$ overhead bulb provided the only illumination. A rotary fan provided ventilation and a continuous masking background throughout all phases of experimentation.

\section{Deprivation}

Procedure

On Day 1 all Ss to be tested at 90 days were rehoused in individual wire cages. Younger Ss were weaned and similarly housed. On Day 2 all Ss were weighed and water bottles were subsequently removed from their cages. Two of each litter of 23and 30-day-old Ss served as yoked weight controls for their respective age groups. Both adults and younger Ss were reduced to $80 \%-85 \%$ of their predeprivation weights. Younger Ss required an additional $10 \mathrm{cc}$ water at the conclusion of each day's training trials to prevent weight loss below $80 \%$ of their yoked controls' mean ad lib weight. This method of depriving young and adult rats to equivalent percent body weights has been previously shown to equate motivational level on the day of testing (Williams \& Campbell, 1961).

\section{Lick Training}

Lick training began on Day 3. A few drops of water were placed into the drinking cup and $S$ was placed into the chamber. After S had emitted 10 to 20 continuously reinforced licks, a stable VI 45-sec response pattern was shaped over six successive 5 -min periods. This procedure was repeated on Day 4 , thereby insuring all Ss of $60 \mathrm{~min}$ of lick training and apparatus adaptation. Thirty-five minutes of training were specific to the VI 45-sec schedule to be used at testing. 


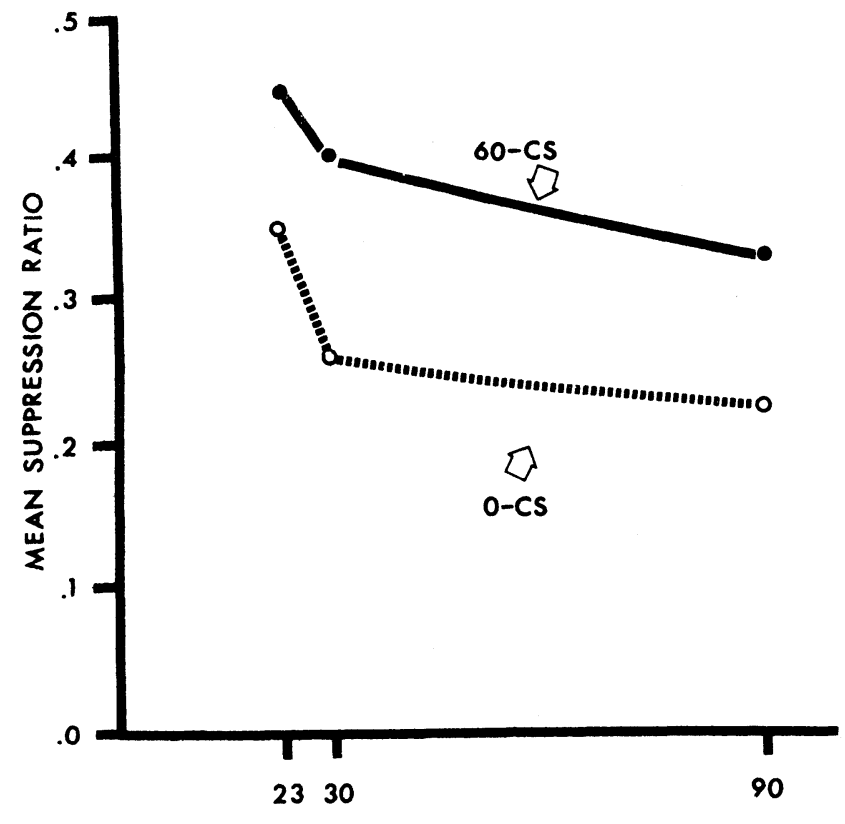

AGE (DAYS)

Fig. 1. Mean lick-suppression ratio as a function of age of the $S$ at testing and preconditioning treatment.

\section{Habituation}

Following lick training, Ss were assigned to one of two treatment groups: (1) 60-CS: Ss experienced a total of $60 \mathrm{CS}$ habituation trials over a 2-day period. Tones were presented to $S$ in the modified apparatus on a VI 1-min schedule. (2) 0-CS: Ss received no preexposure trials to the stimulus but were detained in the exposure apparatus for a time interval equivalent to the total duration of preexposure for $60-\mathrm{CS}$ Ss.

\section{Fear Conditioning}

On Day 5 , following the final preexposure trial, the $60-\mathrm{CS}$ groups received a series of three tone-shock pairings on a VI 35-sec schedule. The 0-CS groups were subdivided into two fear conditioning groups: (1) 0-CS-paired: a control group for which fear conditioning followed the procedure cited above; (2) 0-CS-unpaired: a pseudoconditioning control group in which three unpaired tone and shock presentations occurred. In addition, small numbers of 23-day-old $(\mathrm{N}=6)$ and 90-day-old $(\mathrm{N}=5)$ Ss comprised a shock-alone (SA) group. These Ss received three discrete shocks which followed the time course for the 0 -CS-unpaired group.

\section{Suppression Testing}

Following fear conditioning, $S$ was removed from the apparatus for $3 \mathrm{~min}$ while the chamber was readapted for suppression testing. $S$ was returned to the apparatus and was allowed a $15-\mathrm{min}$ period for the recovery of licking on the VI 45-sec schedule. Immediately following this interval, six successive lick-suppression tests were initiated. Each test consisted of (1) a 30-sec pre-CS interval (tone off) and (2) a 30-sec CS interval (tone on). A 31/2-min no-tone period provided an intertest interval. The number of licks made during the pre-CS and the CS intervals of each test, as well as the time to complete the first $\mathbf{1 0}$ licks per interval, were recorded.

\section{RESULTS}

The CER data of the number of licks emitted per $30-\mathrm{sec}$ interval per test were transformed into suppression ratios (Kamin, 1965). The suppression ratio (SR) was computed as: $\mathrm{SR}=\mathrm{B} / \mathrm{B}+\mathrm{A}$, where $\mathrm{A}$ equals the number of licks during the pre-CS period (tone off) and $B$ equals the number of licks during the CS period (tone on). Hence, a ratio of 0.50 indicated no suppression to tone, while a ratio approaching 0.00 points to a complete suppression of the ongoing licking response. Subsequently, a 2 by 2 by 6 factorial analysis of variance with repeated measures on the last factor was used to analyze these data. Newman-Keuls tests were conducted for individual comparisons of group means, with the alpha level set at 0.05 (cf. Winer, 1962).

Figure 1 displays mean SRs as a function of age and pretraining treatment. A reliable main effect of age was obtained $(p<.05)$. Group means comparisons revealed that only the 90- and 23-day-old Ss differed significantly in overall mean SR. Ss exposed to the CS prior to fear conditioning exhibited less disruption of licking during tone presentations in testing $(\mathrm{p}<.01)$.

Total mean SRs approached 0.50 over successive tests $(p<.001)$. Some variability of mean SRs across trials was reduced by regrouping the data for a second analysis ( 2 by 2 by 3 ANOVA). SRs were obtained for three blocks of two tests each. This analysis indicated that Ss who had experience with the CS licked as infrequently as controls during the first test block. However, they showed a marked recovery to a relatively stable asymptotic performance halfway through testing. Nonexposed Ss showed sustained suppression of licking to the tone.

Analyses of 0-CS-paired and unpaired groups demonstrated a main effect of age on the subsequent amount of suppression to the CS $(\mathrm{p}<.05)$. All Ss tested showed a reliable loss of suppression over successive tests $(p<.01)$. No reliable difference in mean SR was noted between the paired and unpaired procedures. Individual profiles for these two conditions dramatically showed the efficacy of both procedures to produce suppression. These data were reanalyzed for 90- and 23-day-old Ss alone, including SA groups, in an unequal-N 2 by 3 by 6 ANOVA. A main effect of treatment was significant $(p<.01)$. Individual comparisons again showed that the SRs resulting from paired tone-shock presentations were not reliably different from those obtained after unpaired presentations of tone and shock. The SA groups showed less suppression of licking to tone than either of the former groups.

The mean latency to make 10 licks within a $30-\mathrm{sec}$ pre-CS period and the following 30-sec CS interval comprised the fundamental data for a 3 by 2 by 6 by 2 repeated-measures ANOVA. The results of the analysis of latency data corroborate previous SR data: No significant differences in total time to emit 10 licks were associated with the age of the Ss at testing. The 60-CS groups licked reliably more quickly than did the 0-CS Ss during both the pre-CS and CS test intervals $(p<.01)$ and demonstrated no differential latency to emit 10 licking responses between the pre-CS and the CS 
intervals. The 0-CS Ss exhibited longer latencies to lick than did the 60-CS Ss for both test intervals.

The analysis of latency data for paired vs unpaired conditioning groups revealed no differences between them in total time to emit 10 licks. Pre-CS latencies remained shorter than CS latencies. This result was differentially affected by age: Pre-CS latencies were shorter than CS latencies for all age groups, except the 30-day-old Ss. When SA groups (at 23 and 90 days) were added to this analysis, SA groups did not require differential latencies to emit 10 licks for the pre-CS and CS intervals in testing.

\section{DISCUSSION}

The effects of latent inhibition within a CER paradigm have replicated earlier reports. Preconditioning stimulus exposures primarily affected suppression during extinction tests and did not appear on the first test. Specific procedural parameters may have determined the dissociation of the latent inhibition phenomenon between acquisition and extinction.

The tendency for CS preexposures to affect subsequent conditioned lick suppression appeared to vary as a function of the age of the Ss at testing. This result did not achieve significance, but the data profiles suggest that weanling rat pups do not demonstrate the decremental task acquisition characteristic of older CS-habituated Ss. However, these data may provide a reason to extend the Feigley et al findings of age-related differences in habituation of a head-poke response to the context of conditioned responding. Further study of the effects of CS habituation on learning in young and adult organisms seems warranted. Some experimental procedures have commonly employed pretraining apparatus and CS adaptation trials to familiarize the $\mathrm{S}$ with the experimental situation. Implications from the present findings suggest that such procedures may differentially affect subsequent task acquisition for young and adult Ss.

These findings do not replicate the data of Frieman, Frieman, Wright, \& Hegberg (1971) which show that no significant differences in conditioned lick suppression to a tonal CS exist between adult and weanling rats. However, they do correspond favorably with the recent independent findings of Brunner, Roth, \& Rossi (1970) and Frieman, Warner, \& Riccio (1970). Possibly differential amounts of total suppression between young and adult rats in the present study is attributable to a fear conditioning procedure employing only three tone-shock pairings. Such a number of fear conditioning trials has proved adequate to obtain learning in adults (Carlton \& Vogel, 1967). But young Ss may not be sufficiently fearful after only three paired CS-US presentations. They may also require more CS-US pairings to acquire the actual tone-shock contingency.

The lack of a difference between the SRs of the nonhabituated paired vs unpaired treatments may have resulted, at least in part, from the intensity of the CS used in conditioning and in testing. The stimulus was loud. The loudness of the tone may have been great enough to functionally span the interval between tone and shock presentations on the unpaired conditioning procedure. Kamin (1965) has pointed to stimulus intensity as a major factor in determining the efficacy of a trace schedule to produce conditioning. In practice the procedure of three unpaired presentations of tone and shock used in this experiment may have acquired some properties of a trace conditioning schedule via the high intensity of the CS used.

In order to demonstrate that suppression of licking in the presence of the tone was due to fear conditioned to it by the "functional" pairing of CS and US in both the paired and unpaired conditions, and not to a generalized suppressive effect of shock alone, the SA control group was added. The behavior of Ss in the SA groups proved that shock alone did not produce a significant suppression of licking in the presence of the tone in testing. The SA groups remained relatively unsuppressed throughout testing. This finding for both adult and younger Ss mirrors those of Frieman et al (1970). Little suppression to tone in testing results either from (1) pretesting shock presentations alone or (2) pretesting tone presentations alone. Although the latter control was not run in the present study, the Frieman et al results are encouraging in their lack of overall suppression to tone alone.

\section{REFERENCES}

Brunner, R. L., Roth, T. G., \& Rossi, R. R. Age differences in the development of the CER. Psychonomic Science, 1970, 21, 135-136.

Carlton, P. L., \& Vogel, J. R. Habituation and conditioning. Journal of Comparative \& Physiological Psychology, 1967, 63, 348-351.

Feigley, D. A., Parsons, P. J., Hamilton, L. W., \& Spear, N. E. Development of habituation to novel environments in the rat. Journal of Comparative \& Physiological Psychology, 1972, 79, 443-452.

Feigley, D. A., \& Spear, N. E. Effect of age and punishment condition on long-term retention by the rat of active- and passive-avoidance learning. Journal of Comparative \& passive-avoidance learning. Journal of

Frieman, J. P., Frieman, J., Wright, W., \& Hegberg, w. Developmental trends in the acquisition and extinction of conditioned suppression in rats. Developmental Psychology, $1971,4,425-428$.

Frieman, J. P., Warner, J., \& Riccio, D. C. Age differences in conditioning and generalization of fear in young and adult rats. Developmental Psychology, 1970, 3, 119-123.

Kamin, L. J. Temporal and intensity characteristics of the conditioned stimulus. In W. F. Prokasy (Ed.), Classical conditioning: A symposium. New York: Appleton-Century-Crofts, 1965. Pp. 118-147.

Lubow, R. E. Latent inhibition: Effects of frequency of nonreinforced preexposure of the CS. Journal of Comparative \& Physiological Psychology, 1965, 60, 454-457.

Lubow, R. E., \& Moore, A. V. Latent inhibition: The effect of nonreinforced preexposure to the conditioned stimulus. Journal of Comparative \& Physiological Psychology, 1959, 62, 415-419.

Rescorla, $R$. A. Summation and retardation tests of latent inhibition. Journal of Comparative \& Physiological Psychology, 1971, 75, 77-81.

Schulenburg, C. J., Riccio, D.C., \& Stikes, E. R. Acquisition and retention of a passive avoidance response as a function of age in rats. Journal of Comparative \& Physiological Psychology, $1971,74,75-83$.

Siegel, $S$. Latent inhibition and eyelid conditioning. In $A$. $H$. Black and W. F. Prokasy (Eds.), Classical conditiorting II: Current research and theory. New York: Appleton-Century-Crofts, 1972. Pp. 231-247.

Williams, R. A., \& Campbell, B. A. Weight loss and quinine milk ingestion as measures of "hunger" in infant and adult rats. Journal of Comparative \& Physiological Psychology, 1961, 54, 220-222.

Winer, B. J. Statistical principles in experimental design. New York: McGraw-Hill, 1962.

(Received for publication December 3, 1972.) 